\title{
Editorial 61
}

\author{
Eric Scerri ${ }^{1}$
}

Published online: 27 February 2019

(c) Springer Nature B.V. 2019

This edition of the journal is the first of the year 2019, that has been designated as the International Year of the Periodic Table, to mark the 150th anniversary of Mendeleev's first periodic table. "Foundations of Chemistry" is also the title of Mendeleev's famous book, the writing of which was highly instrumental in his arriving at his periodic table of 1869. It is therefore very appropriate that the opening article should be all about Mendeleev's periodic table and in particular the predictions that he made during his career.

Philip Stewart is one of the leading contributors to the growing literature on the foundations of the periodic table. Among other publications he has promoted the writings of Charles Janet and his advocacy of the left-step periodic table (Stewart 2010). Stewart's article in the present issue consists of a close examination of Mendeleev's predictions other than the three that he is most famous for ( $\mathrm{Ga}, \mathrm{Sc}$ and $\mathrm{Ge})$. Whereas I have previously claimed that about half of Mendeleev's predictions did not materialize, Stewart shows here that the full story is a far more complicated one (Scerri 2007).

Jose Antonio Chamizo whose article appears next, is a leading chemical educator in Mexico and also the editor of the journal Educacion Quimica. In addition Chamizo has written a series of articles on what he regards as chemical revolutions. The present article discusses his fourth such revolution which he locates between the years 1945 and 1966.

After reviewing various approaches to the question of the reduction of chemistry the Argentinian philosophers of chemistry, Lombardi et al., propose what they call a bottomup approach that involves the challenge to the notion of individuality that occurs in quantum systems. Moreover, the authors claim that the individuality of quantum particles is lost even in a case as simple as the hydrogen atom.

The Varia section of the issue closes with a brief correction to a previous article by Peter Nelson, a frequent contributor to the journal who is based at the University of Hull in the UK.

The remainder of the issue is a long overdue collection of papers that were delivered in 2015 at the 19th meeting of our society in Rio de Janeiro, that was wonderfully organized by Waldmir Araujo Neto. I will leave it to the guest editors of this special issue, Sebastian Fortin, Camilo Martinez Gonzalez, Alfio Zambon and Waldmir Araujo Neto to introduce the articles in the pages that follow.

Finally, I would like to announce two important conferences. The first is the 23rd annual conference of ISPC that will be held in Turin, Italy from the 15th to the 17th of

Eric Scerri

scerri@chem.ucla.edu

1 Department of Chemistry and Biochemistry, UCLA, Los Angeles, CA 90095, USA 
July (http://www.ispc2019.unito.it/). Secondly, and to return to the theme of Mendeleev, the fourth international conference on the periodic table will be held in St. Petersburg, Russia from July 26th to 28th (https://mendeleev150.ifmo.ru//).

\section{References}

Stewart, P.J.: Charles Janet: unrecognized genius of the periodic system. Found. Chem. 12, 5-15 (2010). https://doi.org/10.1007/s10698-008-9062-5

Scerri, E.: The Periodic Table, Its Story and Its Significance. Oxford University Press, New York (2007)

Publisher's Note Springer Nature remains neutral with regard to jurisdictional claims in published maps and institutional affiliations. 